\title{
Endometrial Flushing Tumor Necrosis Factor Alpha and Interleukin 2 Levels in Women with Polycystic Ovary Syndrome, Leiomyoma and Endometrioma: Comparison with Healthy Controls
}

\section{Tumornekrosefaktor- $\alpha$ - und Interleukin-2-Spiegel in der endo- metrialen Flüssigkeit von Frauen mit polyzystischem Ovarsyndrom, Leiomyomen und Endometriomen: ein Vergleich mit den Werten gesunder Kontrollgruppen}

\section{(ㄷ) (1) (옹 $\ominus$}

Authors

Mustafa Demir ${ }^{1,2}$, Senol Kalyoncu ${ }^{3}$, Onur Ince ${ }^{4}$, Bulent Ozkan $^{5}$, Sefa Kelekci², Gulcan Saglam ${ }^{6}$, Recep Sutcu $^{6}$, Bulent Yilmaz ${ }^{2,4}$

Affiliations

1 Department of Obstetrics and Gynecology, Harran University Faculty of Medicine, Sanliurfa, Turkey

2 Department of Obstetrics and Gynecology, Izmir Katip Celebi University Faculty of Medicine, Izmir, Turkey

3 Department of Obstetrics and Gynecology, TOBB University of Economics and Technology, ETU Hospital, Ankara, Turkey

4 Department of Obstetrics and Gynecology, IVF Unit, Tepecik Education and Research Hospital, Izmir, Turkey

5 Department of Biostatistics, Izmir Katip Celebi University Faculty of Medicine, Izmir, Turkey

6 Department of Biochemistry, Izmir Katip Celebi University Faculty of Medicine, Izmir, Turkey

Key words

endometrial receptivity, interleukin 2, tumor necrosis factor alpha, polycystic ovary syndrome, leiomyoma, endometrioma

\section{Schlüsselwörter}

Empfänglichkeit des endometrischen Gewebes, Interleukin 2, Tumornekrosefaktor- $\alpha$, polyzystisches Ovarsyndrom, Leiomyom, Endometriom

received 26.8 .2018

revised 2.1.2019

accepted 7.1.2019

Bibliography

DOI https://doi.org/10.1055/a-0829-3873

Geburtsh Frauenheilk 2019; 79: 517-523 @ Georg Thieme

Verlag KG Stuttgart · New York | ISSN 0016-5751
Correspondence

Mustafa Demir M.D.

Harran University Faculty of Medicine,

Department of Obstetrics and Gynecology

Şanlıurfa-Mardin Karayolu üzeri 18.km, 63300, Sanliurfa,

Turkey

dr.mdemir35@gmail.com

\section{ABSTRACT}

Introduction An important open question in the literature is whether endometrial receptivity marker levels are different in infertility related diseases than healthy women. The aim of the study is to compare the levels of interleukin two (IL-2) and tumor necrosis factor alpha (TNF- $\alpha$ ) during the implantation window in the endometrial flushing fluid of polycystic ovary syndrome (PCOS), endometrioma, leiomyoma patients with healthy controls.

Material and Methods In this case control study, after obtaining endometrial flushing fluids at mid-luteal phase of ovulatory women with PCOS $(n=20)$, endometrioma $(n=19)$, leiomyoma $(n=20)$ and healthy controls $(n=20), I L-2$ and TNF- $\alpha$ levels were measured using ELISA kits in BioTek ELISA devices.

Results Mean TNF- $\alpha$ levels (ng/mL) were similar for the PCOS (305.6, $p=0.220$ ) and the leiomyoma group (246.3, $\mathrm{p}=0.502$ ) compared to healthy patients (261.1). However, the levels were higher in the endometrioma group (338.2, $p=0,004)$ than the control group (261.1) in a statistically significant way. Mean IL-2 levels $(\mathrm{ng} / \mathrm{mL})$ were significantly lower in the PCOS (290.9, $\mathrm{p}=0.0005)$, the leiomyoma (282.9, $\mathrm{p}=0.0002)$ and the endometrioma patients (229.5, $\mathrm{p}=0.0009$ ) than the control group (416.0).

Conclusion Relative to the control group, endometrial flushing fluid TNF- $\alpha$ levels were significantly higher in endometrioma patients and IL-2 levels were significantly lower in PCOS, 
leiomyoma and endometrioma patients. In benign gynecological diseases, endometrial markers related to infertility seem to show differences in endometrial flushing fluid. Future studies might identify the reference values for these markers, and endometrial markers can be used to diagnose gynecologic disorders causing infertility.

\section{ZUSAMMENFASSUNG}

Einleitung Eine wichtige, in der Literatur oft diskutierte Frage ist, ob Markerwerte, welche die Empfänglichkeit von endometrialem Gewebe anzeigen, anders sind bei Frauen mit Infertilität, verglichen mit gesunden Frauen. Ziel dieser Studie war es, die Interleukin-2-(IL-2) und Tumornekrosefakor- $\alpha$ (TNF- $\alpha$-)Spiegel in der endometrialen Spülflüssigkeit während des Implantationsfensters bei Frauen mit polyzystischem Ovarsyndrom (PCOS), Endometriomen oder Leiomyomen mit den Werten einer gesunden Kontrollgruppe zu vergleichen.

Material und Methoden In dieser Fallkontrollstudie wurden die IL-2- and TNF- $\alpha$-Werte von Frauen mit PCOS $(n=20)$, Endometriomen $(n=19)$ und Leiomyomen $(n=20)$ gemessen und mit den Werten einer gesunden Kontrollgruppe $(n=20)$ verglichen. Die Werte wurden während der Lutealphase in der endometrialen Spülflüssigkeit der Frauen gemessen. ELISA Kits und BioTek ELISA-Geräte wurden zur Messung der IL-2- und TNF- $\alpha$-Spiegel verwendet.
Ergebnisse Die durchschnittlichen TNF- $\alpha$-Werte $(\mathrm{ng} / \mathrm{mL})$ der PCOS-Gruppe $(305,6, p=0,220)$ und der Leiomyomgruppe $(246,3, p=0,502)$ waren ähnlich; beide waren höher als die in der gesunden Kontrollgruppe gemessenen Werte $(261,1)$. Die Werte der Endometriomgruppe $(338,2, p=0,004)$ waren noch höher verglichen mit der Kontrollgruppe $(261,1)$, und dieser Unterschied war statistisch signifikant. Durchschnittliche IL-2-Werte $(\mathrm{ng} / \mathrm{mL})$ waren wesentlich niedriger in der PCOS-Gruppe $(290,9, \quad p=0,0005)$, der Leiomyomgruppe $(282,9, p=0,0002)$ und der Endometriomgruppe (229,5, $p=0,0009$ ) verglichen mit der Kontrollgruppe $(416,0)$.

Schlussfolgerung Relativ zur Kontrollgruppe waren die TNF$\alpha$-Werte in der endometrialen Spülflüssigkeit signifikant höher in der Patientinnengruppe mit Endometriomen, und die IL-2-Werte waren signifikant niedriger in den Patientinnen mit Leiomyomen und Endometriomen. Bei gutartigen gynäkologischen Erkrankungen scheinen sich die Werte fertilitätsassoziierter, in der endometrialen Spülflüssigkeit gemessener Marker von den Werten gesunder Frauen zu unterschieden. Die Referenzwerte dieser Marker könnten Gegenstand zukünftiger Studien sein, und die endometrialen Marker könnten zur Diagnose von gynäkologischen Störungen, die ursächlich für Infertilität sind, herangezogen werden.

\section{Introduction}

Endometrial receptivity (ER) indicates the period when luminal epithelium is suitable for blastocyst implantation. Development of receptive endometrium depends on the satisfactory change of estrogen-processed endometrium in response to progesterone secretion. It has been found that integrins and their ligands (e.g. osteopontin), mucins, growth factors (HB-EGF), homeobox transcription factors (HOXA gene products), lipids, cytokines (Leptin, LIF, IL-1, IL-11) and other molecules take part in this process [1 - 3] and the focus of this study, cytokines regulate potent intercellular signals that conduct feto-maternal communication in endometrial cells and have a critical importance in this process.

There are ongoing studies that aim to develop alternative treatment strategies in order to balance cytokine levels by external cytokine support or inhibition [4]. One cytokine that has been investigated for this purpose is tumor necrosis factor alpha (TNF$\alpha$ ) [5]. Existing studies suggest that TNF- $\alpha$ inhibits blastocyst vitality, growth and metamorphosis before implantation [6].

Interleukin-2 (IL-2), another cytokine secreted by T cells during antigen presentation responsible for antigen specific cell proliferation, is also under study. It increases the differentiation and proliferation of other immune cells (growth and anticore synthesis stimulant for NK, LAK and B cells) and apoptotic death of T-cells activated by antigen [7]. There are few studies in the literature that investigate the relationship between IL-2 and ER, even though it has a close relationship with the cells that have roles in feto-maternal immune regulation $[8,9]$.
Benign gynecological disorders including endometriosis, hydrosalpinx, leiomyoma, and polycystic ovary syndrome (PCOS) are associated with decreased fertility cycle outcomes and impaired ER [10]. An important debate in the literature is whether ER marker levels are different in the endometrium of women with infertility-causing diseases compared with healthy women.

One method for assessing endometrial micro-environment is measuring the marker levels in endometrial flushing fluid. While endometrial flushing has no certain diagnostic use in clinics and is not as accurate and sensitive as immunohistochemistry, it is non-invasive and easy to implement and it has been widely used in the clinical literature to assess intra-uterine microenvironment and to comment on molecular mechanisms. It is well tolerated by the patients and preovulatory use of it was suggested as a treatment model for women with unexplained fertility [11].

This study compares TNF- $\alpha$ and IL-2 levels in the endometrial flushing fluid of patients with polycystic ovary syndrome, endometrioma and leiomyoma with healthy women. It investigates whether endometrial receptivity markers differ across these groups and attempts to provide insights into the molecular mechanisms of these diseases.

\section{Materials and Methods}

\section{Patients and the ethical approval}

The subjects in the study were patients who volunteered in Izmir Katip Celebi University Ataturk Education and Research Hospital outpatient gynecology clinic. The study was conducted between 
January and June 2013. Izmir Katip Celebi University Ethics Commission approved of the study which was funded by Izmir Katip Celebi University Scientific Research Projects Coordination Unit (2013-T1-TSBP-11). All subjects were informed in detail about the research project verbally and their written informed consent was obtained. The study was conducted with patients that were also part of another study [12]. This other study focused on the levels of structural proteins and progesterone regulated molecules ( $\alpha \mathrm{V} \beta 3$ integrin, glycodelin and PGF $2 \alpha$ ). In contrast, the current study focuses on the comparison of 2 important immunomodulatory cytokines, TNF- $\alpha$ and IL-2 levels among healthy patients and patients with benign gynecological diseases.

The subjects included in the study were between the ages of 20 to 40, and either had polycystic ovary syndrome, endometrioma and uterine myoma or were healthy subjects without any gynecological disorders. They were also required to have regular periods (between 28-34 days, variation $\leq 3$ days between cycles). The subjects did not have any intrauterine devices, did not use hormonal contraception or medications related to their gynecologic disease or that may affect the endometrium, and had the intellectual capacity to comprehend the information about the study and provide written consent.

The exclusion criteria for volunteers: smokers, subjects being pregnant, having pelvic infection symptoms, having luteal phase serum progesterone levels $<3 \mathrm{ng} / \mathrm{dL}$ seven days before their expected menstruation date and subjects opting out of the study. In addition, patients who had findings suggestive of pathologies associated with changes in ER markers, such as hydrosalpinx, adenomyosis, endometrial pathologies (submucous fibroids, endometrial polyps, etc.) were excluded from the study. The patients with concomitant gynecologic pathologies according to diagnosis criteria of stated below (i.e. patients with both myoma and endometrioma) were also not included. The evaluation of these pathologies were made based on transvaginal ultrasound (TV-USG) (Medison SonoAce, AM Company Co. Ltd., South Korea) and saline infusion sonography (SIS) that were routinely performed on patients after endometrial fluid sampling.

\section{Methods and outcomes of interest}

The study was conducted in case control design. For each group, the first 20 patients that attended Izmir Katip Celebi University Ataturk Education and Research Hospital between January and June 2013, satisfied the inclusion criteria and did not violate the exclusion criteria were included in the study. During that period, we only had 19 endometrioma patients.

The first group in the study included 20 subjects with polycystic ovary syndrome who all had a specific phenotype (hyperandrogenism plus ultrasound criteria according to Rotterdam criteria [13]) and did not have ovulatory disorders according to their serum progesterone levels on the 21st day of their cycle measured on their first evaluation. The second group included 20 patients with at least one intramural leiomyoma with 3 to $10 \mathrm{~cm}$ diameter as measured on TV-USG. The third group included 19 endometrioma patients who satisfied all three of the following criteria:
1. pelvic pain,

2. dysmenorrhea,

3. at least one unilocular cyst larger than $3 \mathrm{~cm}$ on TV-USG with diffuse homogeneous ground-glass echoes due to probable hemorrhagic debris.

Lastly, the control group included 20 otherwise healthy women who were chosen among the patients who attended to outpatient gynecology clinic with tubal ligation demand. They were required to be at reproductive age, have no gynecologic symptoms and no pathologic findings on TV-USG (inclusive of leiomyoma, endometriotic nodules, polycystic ovaries, abnormally thickened endometrium or free fluid in the Douglas pouch). Fertility state of the patients were not used as criteria in defining the groups.

The main outcome measure of the study was TNF- $\alpha$ and IL-2 levels in endometrial flushing fluid. The levels of these markers in PCOS, leiomyoma and endometrioma patients were compared with the control group.

We measured levels of markers by endometrial flushing which is a commonly used method in the clinical literature to assess intra-uterine microenvironment and molecular mechanisms. In particular, the patients were cautioned against having sexual intercourse until the sampling of endometrial fluid in the current menstruation cycle and they were called to the clinic for the sampling seven days before their expected menstruation date on the time corresponding to their midluteal phase. After confirmation of ovulation based on blood progesterone levels, endometrial fluid sampling was performed following a procedure similar to saline infusion sonography technique and adopted from an earlier study [14]. The patients were placed in dorsal lithotomy position. A bivalve disposable speculum was inserted into the vagina and to eliminate potential contaminants, the cervix was cleaned with sterile saline. Then, a menstrual regulating cannula (4 mm diameter) was introduced into the uterine cavity through the cervical canal. A syringe was then used to instill $5 \mathrm{ml}$ of sterile saline into the uterine cavity. The uterine contents were aspirated quickly. The procedure was repeated two times, after which the samples were collected in separate Eppendorfs, centrifuged and then stored at $-80^{\circ} \mathrm{C}$. The subjects were kept under observation for about half an hour after the endometrial fluid sampling.

After endometrial fluid samples were collected from all patients, TNF- $\alpha$ and IL-2 levels were measured by using Eastbiopharm (Hangzhou Eastbiopharm Co. Ltd./China) ELISA kits (TNFa lot: 20130924, IL-2 lot: 20130924) in BioTek ELISA devices. For all 79 patients, the same kits were used for the same markers until the end of data collection.

\section{Statistical analysis}

For statistical analysis, SPSS 23.0 (SPSS Inc., Chicago, IL) software was used. The normality of the data was tested with Shapiro-Wilks test and homogeneity of variances was tested with Levene's test. Accordingly, Mann-Whitney U Test or Independent Sample T Test were used to compare the three groups' TNF- $\alpha$ and IL-2 levels with the control group. As the mean age values differ significantly among the groups, to check whether the differences of TNF- $\alpha$ and IL-2 levels between the groups depend on age or not, correlation analysis with Spearman correlation coefficient was per- 
formed. Two-tailed p-values below 0.05 were assumed to be statistically significant. Values are presented in median (min-max) [mean \pm SD] format.

\section{Results}

There were 79 subjects and all of them tolerated endometrial fluid sampling well. No subject had early (uterine rupture, etc.) or late (pelvic infection, etc.) complications, and only one subject had pelvic pain that required two hours of observation.

\section{Descriptive parameters}

- Table 1 summarizes the demographic data and baseline serum progesterone levels. The mean age of patients with PCOS, uterine myoma, endometrioma and the control group were $28.90 \pm 5.45$, $37.25 \pm 2.73,32.84 \pm 6.62$ and $32.15 \pm 5.18$, respectively. Compared to the control group, the mean age was lower in the PCOS $(p=0.045)$ and higher in the myoma patients in a statistically sig- nificant way $(p=0.001)$. The mean age difference was not statistically significant between the endometrioma patients and the control group $(p=0.717)$. As for mean body mass index $\left(\mathrm{kg} / \mathrm{m}^{2}\right)$, relative to the control group, it was lower in the endometrioma group $(p=0.005)$ and similar for the uterine myoma $(p=1.0)$ and the PCOS groups $(p=0.205)$.

Mid-luteal phase serum progesterone level $(\mathrm{ng} / \mathrm{ml})$ was similar in the leiomyoma (9.61, p = 0.745) and the $\operatorname{PCOS~}(9.47, \mathrm{p}=0.978)$ groups relative to the control group (8.75). It was, however, lower in the endometrioma group (6.26) than in the control group $(p=0.030)$ in a statistically significant way. Gravida and parity values were significantly lower in all three groups than the control group ( $\triangleright$ Table 1$)$.

\section{Comparison of endometrial receptivity markers}

- Table 2 shows comparison of endometrial flushing fluid TNF- $\alpha$ and IL-2 levels of the three gynecologic disease groups with the control group. Comparisons of the TNF- $\alpha$ levels $(\mathrm{ng} / \mathrm{ml})$ in the

- Table 1 Demographic and baseline data including comparison of gynecologic diseases with control group.

\begin{tabular}{|c|c|c|c|c|}
\hline & $P \cos (n=20)$ & Leiomyoma $(n=20)$ & Endometrioma $(n=19)$ & Control $(n=20)$ \\
\hline \multirow[t]{2}{*}{ Age (year) } & $29(20-38)$ & $38(32-40)$ & $34(20-40)$ & $34(22-39)$ \\
\hline & {$[28.90 \pm 5.45]^{*}$} & {$[37.25 \pm 2.73]^{* * *}$} & {$[32.84 \pm 6.62]$} & {$[32.15 \pm 5.18]$} \\
\hline \multirow[t]{2}{*}{$\mathrm{BMI}(\mathrm{kg} / \mathrm{m} 2)$} & $26(18.10-35.30)$ & $25(19.50-35)$ & $21.4(17.5-27.3)$ & $24.7(19-31.2)$ \\
\hline & {$[26.65 \pm 4.74]$} & {$[24.93 \pm 4.01]$} & {$[21.71 \pm 2.92]^{* *}$} & {$[24.92 \pm 3.67]$} \\
\hline \multirow[t]{2}{*}{ Gravidity (n) } & $0.5(0-1)$ & $2(0-5)$ & $1(0-4)$ & $3(2-8)$ \\
\hline & {$[0.50 \pm 0.51]^{* * *}$} & {$[1.75 \pm 1.52]^{* * *}$} & {$[0.97 \pm 1.22]^{* * *}$} & {$[3.75 \pm 1.77]$} \\
\hline \multirow[t]{2}{*}{ Parity (n) } & $0(0-1)$ & $1(0-3)$ & $0(0-3)$ & $3(1-8)$ \\
\hline & {$[0.35 \pm 0.49]^{* * *}$} & {$[1.5 \pm 1.04]^{* * *}$} & {$[0.79 \pm 1.03]^{* * *}$} & {$[2.90 \pm 1.37]$} \\
\hline \multirow[t]{2}{*}{ Progesteron (ng/ml) } & $8.39(3.71-19)$ & $7.04(3.47-21.73)$ & $4.6(3-14.49)$ & $8.53(3.75-17.77)$ \\
\hline & {$[9.47 \pm 4.17]$} & {$[9.61 \pm 5.56]$} & {$[6.26 \pm 3.57]^{*}$} & {$[8.75 \pm 3.67]$} \\
\hline \multicolumn{5}{|c|}{ Values are presented as median (min-max) [mean \pm SD]; PCOS = Polycystic ovary syndrome; BMI = body mass index. } \\
\hline \multicolumn{5}{|c|}{$\begin{array}{l}\text { Three gynecologic diseases are compared with control group separately and p-values were calculated with Mann-Whitney U Test or Independent Sample T } \\
\text { Test, accordingly. The significantly different diseases compared to control group for each variable was marked with asterisks. Levels of statistical significance } \\
\text { were given below. }\end{array}$} \\
\hline \multicolumn{5}{|c|}{${ }^{*} \mathrm{p} \leq 0.05,{ }^{* *} \mathrm{p} \leq 0.01,{ }^{* * *} \mathrm{p} \leq 0.001$} \\
\hline
\end{tabular}

- Table 2 Comparison of gynecologic diseases' IL-2 and TNF- $\alpha$ levels with control group.

\begin{tabular}{|l|l|l|l|l|}
\hline \multirow{2}{*}{$\mathrm{TNF}-\alpha(\mathrm{ng} / \mathrm{mL})$} & PCOS $(\mathbf{n}=\mathbf{2 0})$ & Leiomyoma $\mathbf{( n = 2 0 )}$ & Endometrioma $(\mathbf{n}=\mathbf{1 9})$ & Control $(\mathbf{n}=\mathbf{2 0})$ \\
\hline \multirow{2}{*}{$\mathrm{LL}-2(\mathrm{ng} / \mathrm{mL})$} & $271.1(110.4-594.1)$ & $266.1(67.8-351.1)$ & $323.9(211.4-499.1)$ & $258.9(106.4-460.1)$ \\
\hline & {$[305.6 \pm 140.0]$} & {$[246.3 \pm 62.8]$} & {$[338.2 \pm 84.0]^{* *}$} & {$[261.1 \pm 74.8]$} \\
\hline & $285.0(164.6-422.6)$ & $303.0(148.3-404.8)$ & $82.9(4.2-1355.8)$ & $426.33(129.5-589.4)$ \\
\hline & {$[290.9 \pm 75.2]^{* * *}$} & {$[282.9 \pm 70.2]^{* * *}$} & {$[229.5 \pm 334.9]^{* * *}$} & {$[416.0 \pm 123.4]$} \\
\hline
\end{tabular}

Values are presented as median (min-max) [mean \pm SD]; PCOS = Polycystic ovary syndrome; BMI = body mass index; TNF- $\alpha=$ Tumor Necrosis Factor Alpha; IL-2 = Interleukin 2 .

Three gynecologic diseases are compared with control group separately and p-values were calculated with Mann-Whitney U Test or Independent Sample T Test, accordingly. The significantly different diseases compared to control group for each variable was marked with asterisks. Levels of statistical significance were given below.

${ }^{*} \mathrm{p} \leq 0.05,{ }^{* *} \mathrm{p} \leq 0.01,{ }^{* * *} \mathrm{p} \leq 0.001$ 
PCOS and leiomyoma groups with the control group do not reveal significant differences ( $p$ values were 0.220 and 0.502 , respectively). The endometrioma group had significantly higher TNF- $\alpha$ levels $(338.2 \mathrm{ng} / \mathrm{ml})$ than the control group $(261.1 \mathrm{ng} / \mathrm{ml}, \mathrm{p}=0.004)$. However, mean IL-2 levels $(\mathrm{ng} / \mathrm{ml})$ were significantly lower in the PCOS $(p=0.0005)$, leiomyoma $(p=0.0002)$ and endometrioma patients $(p=0,0009)$ than in the control group $(416.0 \pm 123.4)$.

As the mean age values differ significantly between the groups, the association of age with TNF- $\alpha$ and IL-2 levels were investigated. The correlation between age and TNF- $\alpha(r=0.126$, $p=0.270)$ and between age and IL-2 $(r=-0.038, p=0.741)$ were found to be insignificant.

\section{Discussion}

In this case-control study, endometrial flushing fluid levels of TNF$\alpha$ and IL- 2 were compared for subjects with polycystic ovarian syndrome, endometrioma and uterine leiomyoma with the healthy controls. According to our findings, PCOS and leiomyoma patients had significantly lower IL-2 and similar TNF- $\alpha$ levels relative to healthy patients, while endometrioma patients had higher TNF- $\alpha$ levels and lower IL-2 levels.

In our 2017 study, we had chosen to evaluate three cell signaling molecules that have impact on endometrial receptivity with mostly paracrine effect [12]. That study included structural proteins and progesterone-regulated molecules. This previous study found that $\alpha \mathrm{V} \beta 3$ integrin and glycodelin levels were higher in the endometrioma and PGF2 $\alpha$ was higher in the PCOS patients than the control group in a statistically significant way [12].

Beside these molecules, cytokines also play an important role for progesterone-regulated ER and embryo development. The motivation for investigating cytokines comes from studies that indicate its role in fostering a healthy intrauterine environment through their autocrine, paracrine and endocrine (systemic and immunomodulatory) effects. For example, TNF- $\alpha$, an immunomodulatory cytokine is conjectured to be an appropriate signal for the closing of the implantation window and preparation for menstrual shedding [15]. In vitro studies claimed that TNF- $\alpha$ protects the embryo from teratogenic effects [16] and regulates invasion characteristics of trophoblast by regulating MMP 2 and MMP 9 [17]. On the other hand, an animal study of TNF- $\alpha$ has found it to be a pro-inflammatory cytokine that triggers immunological pregnancy loss $[18,19]$.

While there are many studies that systemically investigate the relationship of serum TNF- $\alpha$ levels with benign gynecologic diseases, TNF- $\alpha$ levels within uterine cavity of women with gynecologic diseases has not received sufficient attention. Endometrioma or endometriosis are important examples of such diseases which have received limited attention. Minici et al. [20] and Iwabe et al. found that the concentrations of TNF- $\alpha$ were significantly higher in peritoneal fluid from patients with endometriosis than that of patients without endometriosis [21]. Iwabe et al. also conjectured that TNF- $\alpha$ might inhibit the development of preimplantation embryo and impair sperm function [21]. In another in-vitro study, the adherence of endometrial stromal cells to mesothelial cells increased significantly when mesothelial cells were exposed to TNF- $\alpha$ nutrients. This finding highlights TNF- $\alpha$ 's role in the de- velopment of endometriosis [22]. Furthermore, it suggests that, the higher level of TNF- $\alpha$ that the current study identifies might also be playing a role in the pathogenesis of infertility associated with endometriosis. Thus, patients with endometriosis might benefit from the administration of TNF- $\alpha$ receptor blockers as mentioned before [23].

There is no study that investigates the TNF- $\alpha$ levels in the endometrial cavity of PCOS patients. The current study finds that TNF- $\alpha$ level in uterine irrigation fluid of PCOS patients is not different from the control group. Nevertheless, the relationship between TNF- $\alpha$ levels and PCOS has been subject to a number of earlier studies. Younis et al. found that the blood TNF- $\alpha$ levels of PCOS and unexplained infertility patients are significantly higher than the healthy control group [24]. Other studies have also found that TNF- $\alpha$ is higher in normal-weight women with PCOS and is even higher in overweight/obese adolescents with PCOS $[25,26]$. While Thathapudi et al. found that TNF- $\alpha$ system might contribute to the pathogenesis of hyperandrogenism, obesity, and insulin resistance in PCOS [27], a meta-analysis found that TNF- $\alpha$ polymorphism may not be associated with PCOS risk [28].

Despite the studies that did not find differences in the expression of endometrial genes that play a role in implantation between intramural myoma patients and fertile groups [29], problems related to ER and fertility were always suspected and studied in patients with myomas. TNF- $\alpha$ is an important cytokine for ER and it was also suggested that it might be playing an important role in regulating apoptosis in leiomyoma cells [30]. Inagaki found that the mean level of TNF- $\alpha$ in uterine cavity was higher in leiomyoma patients than adenomyosis and endometrial polyp patients and the control group [31]. Nevertheless Ben-Nagi et al. found that TNF- $\alpha$ levels in mid-luteal phase uterine flushing of submucosal myoma patients is lower than the control group, but the difference was not statistically significant [14]. The results of the current study are consistent with findings of the study by BenNagi et al. [14]. However, more research is needed to clarify the relationship between TNF- $\alpha$ levels and feto-maternal immunologic regulation in myoma patients.

T regulatory cells $\left(T_{\text {reg }} s\right)$ play an important role in implantation and determination of peripheral tolerance [32]. $T_{\text {reg }} s$ are critical for the success of implantation and their absence might end pregnancy in early-mid gestation [33]. Animal studies have shown that IL-2 modulates $\mathrm{T}_{\text {regs }}$ and contributes to $\mathrm{T}_{\text {regs }}$ survival, proliferation and function. Consequently, trials of low-dose IL-2 treatment in mice substantially improved pregnancy outcome [34]. Nevertheless, Guneet Makkar et al. compared natural cycle and stimulated cycle patients and concluded that increased expression of IL-2 in the peri-implantation endometrium may account for the lower implantation rate in excessive responders (subjects with $E_{2}$ concentration on the day of hCG was $>20000 \mathrm{pmol} /$ ) [35]. In contrast to these results based on endometrial biopsy, the IL-2 levels in uterine flushing were not significantly different [35].

The findings in the literature on the IL-2 level in peritoneal fluid of endometriosis patients and its relationship with infertility are inconsistent. Some studies find IL-2 level is significantly higher in infertile women $[36,37]$ while others do not find a significant difference [38]. 
In patients with PCOS, the stimulated production of IL-2 was found to be lower in peripheral circulation, irrespective of BMI [39]. Krishna et al. found that $T_{\text {reg }}$ s which play an important role in efficient reproductive function due to their immunosuppressive effect are lower in PCOS patients and explained this finding with the inherent hyporesponsiveness to IL-2. It has been conjectured that IL-2 based therapies may help counter PCOS complications [40].

There are few studies on IL-2 that investigate ER in human endometrial tissue or endometrial flushing fluid. A 2013 study found a lower expression of IL-2 in curettage material of women with spontaneous miscarriage relative to women with voluntary termination of pregnancy and highlighted involvement of specific Th1 cytokines on the implantation process [41]. The current study contributes to this debate and is also the first study to investigate endometrial flushing IL-2 levels for ER in PCOS, leiomyoma and endometrioma patients. The results show that during the implantation period IL-2, which plays an important role in the regulation of Th, $\mathrm{T}_{\text {reg }} \mathrm{S}$, Tc, and NK cells, is lower in endometrioma, PCOS and leiomyoma patients than the control group in a statistically significant way. More studies are needed to better understand the relationship between the reduced IL-2 levels and impaired receptivity in PCOS, leiomyoma and endometrioma patients.

Limitations of the current study include the differences between groups regarding baseline demographic data and not using the infertility state as a criterion for including patients in different benign gynecologic disease groups. These limitations make it difficult to associate these markers' levels with infertility and reach a conclusive result. At the same time, age is not correlated with TNF- $\alpha$ and IL-2 levels, suggesting that the differences between groups are not driven by age differences.

Another potential concern is that analyzing ER markers with immunohistochemistry using endometrial tissue as in the previous studies $[41,42]$ would have given more accurate results than the uterine flushing technique we employ. On the flip side, endometrial flushing technique is cheaper, less invasive and more acceptable to patients, and hence would arguably be more feasible for routine.

Lastly, the timing for carrying out the endometrial biopsies might be a concern. The literature commonly describes implantation window as $\mathrm{LH}+6$ to $\mathrm{LH}+11$, collects tissue specimens between these days [43], and test the urine for LH surge [14]. We did not have the chance to use these kits on patients. To address this concern we narrowed down the criteria for patients' periods (regular periods between 28-34 days, variation $\leq 3$ days between cycles). Endometrial fluid sampling was carried out 7 days before the following presumed menstruation start after confirmation of ovulation based on blood progesterone levels ( $\geq 3 \mathrm{ng} / \mathrm{dl}$ ).

\section{Conclusion}

In PCOS and leiomyoma, TNF- $\alpha$ levels were not found to be significantly different from the control patients. However, decreased IL2 levels in PCOS, leiomyoma and endometrioma patients and increased TNF- $\alpha$ levels in endometrioma patients might be playing a role in infertility and impaired endometrial implantation associated with these diseases. These findings provide hints for molecu- lar mechanisms underlying these diseases and contributes to the literature that investigates ways to diagnose these diseases with auxiliary methods for clinical purposes. More studies on the relationship between these cytokines and infertility are needed to shed light on this question.

\section{Acknowledgements}

The authors report no conflicts of interest. The authors alone are responsible for the content and writing of this article.

\section{Conflict of Interest}

The authors declare that they have no conflict of interest. This study was funded by Scientific Research Projects Coordination Unit of the Izmir Katip Celebi University (Project no: 2013-T1-TSBP-11).

\section{References}

[1] Aghajanova L, Simón C, Horcajadas JA. Are favorite molecules of endometrial receptivity still in favor? Expert Rev Obstet Gynecol 2008; 3: 487-501

[2] Giudice LC. Potential biochemical markers of uterine receptivity. Hum Reprod 1999; 14 (Suppl. 2): 3-16

[3] Wang H, Dey SK. Roadmap to embryo implantation: clues from mouse models. Nat Rev Genet 2006; 7: 185-199

[4] Erten G. Sitokinler. In: Camcıoğlu Y, ed. Sempozyum Dizisi No: 80, Bağışıklık Sistemi ve Yetersizlikleri. İstanbul: i.ü. Cerrahpaşa Tıp Fakültesi Sürekli Tıp Eğitimi Etkinlikleri; 2013: 55-62

[5] Ghosh D, Sengupta J. Recent developments in endocrinology and paracrinology of blastocyst implantation in the primate. Hum Reprod Update 1998; 4: 153-168

[6] Lalitkumar PG, Sengupta J, Ghosh D. Endometrial tumor necrosis factor alpha (TNFalpha) is a likely mediator of early luteal phase mifepristonemediated negative effector action on the preimplantation embryo. Reproduction 2005; 129: 323-335

[7] Abbas AK, Lichtman AH. Cytokines. In: Abbas AK, Lichtman AH. Cellular and molecular Immunology. 5th ed. Saunders; 2005: 264-267

[8] Soni C, Karande AA. Glycodelin-A interferes with IL-2/IL-2R signalling to induce cell growth arrest, loss of effector functions and apoptosis in Tlymphocytes. Hum Reprod 2012; 27: 1005-1015

[9] Hamai Y, Fujii T, Yamashita T et al. Evidence for an elevation in serum interleukin-2 and tumor necrosis factor-alpha levels before the clinical manifestations of preeclampsia. Am J Reprod Immunol 1997; 38: 89-93

[10] Donaghay M, Lessey BA. Uterine receptivity: alterations associated with benign gynecological disease. Semin Reprod Med 2007; 25: 461-475

[11] Maheux-Lacroix S, Dodin S, Moore L et al. Preovulatory uterine flushing with saline as a treatment for unexplained infertility: a randomised controlled trial protocol. BMJ Open 2016; 6: e009897

[12] Demir M, Ince O, Ozkan B et al. Endometrial flushing alphaVbeta3 integrin, glycodelin and PGF2alpha levels for evaluating endometrial receptivity in women with polycystic ovary syndrome, myoma uteri and endometrioma. Gynecol Endocrinol 2017; 33: 716-720

[13] Rotterdam ESHRE/ASRM-Sponsored PCOS Consensus Workshop Group. Revised 2003 consensus on diagnostic criteria and long-term health risks related to polycystic ovary syndrome. Fertil Steril 2004; 81: 19-25

[14] Ben-Nagi J, Miell J, Mavrelos D et al. Endometrial implantation factors in women with submucous uterine fibroids. Reprod Biomed Online 2010; 21: $610-615$

[15] Tabibzadeh S. Molecular control of the implantation window. Hum Reprod Update 1998; 4: 465-471 
[16] Toder V, Fein A, Carp H et al. TNF-alpha in pregnancy loss and embryo maldevelopment: a mediator of detrimental stimuli or a protector of the fetoplacental unit? J Assist Reprod Genet 2003; 20: 73-81

[17] Staun-Ram E, Goldman S, Gabarin D et al. Expression and importance of matrix metalloproteinase 2 and 9 (MMP-2 and -9) in human trophoblast invasion. Reprod Biol Endocrinol 2004; 2: 59

[18] Arck PC, Troutt AB, Clark DA. Soluble receptors neutralizing TNF-alpha and IL-1 block stress-triggered murine abortion. Am J Reprod Immunol 1997; 37: 262-266

[19] Stefanski AL, Specker C, Fischer-Betz R et al. Maternal Thrombophilia and Recurrent Miscarriage - Is There Evidence That Heparin is Indicated as Prophylaxis against Recurrence? Geburtsh Frauenheilk 2018; 78: 274282

[20] Minici F, Tiberi F, Tropea A et al. Endometriosis and human infertility: a new investigation into the role of eutopic endometrium. Hum Reprod 2008; 23: 530-537

[21] Iwabe T, Harada T, Terakawa N. Role of cytokines in endometriosis-associated infertility. Gynecol Obstet Invest 2002; 53 (Suppl. 1): 19-25

[22] Zhang RJ, Wild RA, Ojago JM. Effect of tumor necrosis factor-alpha on adhesion of human endometrial stromal cells to peritoneal mesothelial cells: an in vitro system. Fertil Steril 1993; 59: 1196-1201

[23] Toth B, Würfel W, Bohlmann M et al. Recurrent Miscarriage: Diagnostic and Therapeutic Procedures. Guideline of the DGGG, OEGGG and SGGG (S2 k-Level, AWMF Registry Number 015/050). Geburtsh Frauenheilk 2018; 78: 364-381

[24] Younis A, Hawkins K, Mahini H et al. Serum tumor necrosis factor-alpha, interleukin-6, monocyte chemotactic protein-1 and paraoxonase-1 profiles in women with endometriosis, PCOS, or unexplained infertility. J Assist Reprod Genet 2014; 31: 1445-1451

[25] Gonzalez F, Thusu K, Abdel-Rahman E et al. Elevated serum levels of tumor necrosis factor alpha in normal-weight women with polycystic ovary syndrome. Metabolism 1999; 48: 437-441

[26] Pawelczak M, Rosenthal ], Milla S et al. Evaluation of the pro-inflammatory cytokine tumor necrosis factor-alpha in adolescents with polycystic ovary syndrome. J Pediatr Adolesc Gynecol 2014; 27: 356-359

[27] Thathapudi S, Kodati V, Erukkambattu J et al. Tumor necrosis factor-alpha and polycystic ovarian syndrome: a clinical, biochemical, and molecular genetic study. Genet Test Mol Biomarkers 2014; 18: 605-609

[28] Guo R, Zheng Y, Yang J et al. Association of TNF-alpha, IL-6 and IL-1beta gene polymorphisms with polycystic ovary syndrome: a meta-analysis. BMC Genet 2015; 16: 5

[29] Horcajadas JA, Goyri E, Higon MA et al. Endometrial receptivity and implantation are not affected by the presence of uterine intramural leiomyomas: a clinical and functional genomics analysis. J Clin Endocrinol Metab 2008; 93: 3490-3498
[30] Kurachi O, Matsuo H, Samoto T et al. Tumor necrosis factor-alpha expression in human uterine leiomyoma and its down-regulation by progesterone. J Clin Endocrinol Metab 2001; 86: 2275-2280

[31] Inagaki N, Ung L, Otani T et al. Uterine cavity matrix metalloproteinases and cytokines in patients with leiomyoma, adenomyosis or endometrial polyp. Eur J Obstet Gynecol Reprod Biol 2003; 111: 197-203

[32] Günther V, Alkatout I, Junkers W et al. Active Immunisation with Partner Lymphocytes in Female Patients Who Want to Become Pregnant - Current Status. Geburtsh Frauenheilk 2018; 78: 260-273

[33] van Mourik MS, Macklon NS, Heijnen C]. Embryonic implantation: cytokines, adhesion molecules, and immune cells in establishing an implantation environment. J Leukoc Biol 2009; 85: 4-19

[34] Chen T, Darrasse-Jeze G, Bergot AS et al. Self-specific memory regulatory T cells protect embryos at implantation in mice. J Immunol 2013; 191 : 2273-2281

[35] Makkar G, $\mathrm{Ng} \mathrm{EH}$, Yeung WS et al. Excessive ovarian response is associated with increased expression of interleukin-2 in the periimplantation endometrium. Fertil Steril 2009; 91: 1145-1151

[36] Hill JA, Anderson DJ. Lymphocyte activity in the presence of peritonea fluid from fertile women and infertile women with and without endometriosis. Am J Obstet Gynecol 1989; 161: 861-864

[37] Zhang S, Wang $\mathrm{H}$, Meng $\mathrm{C}$. [Alteration of peritoneal lymphocyte transformation and its interleukin-2 release in patients with infertility and endometriosis]. Zhonghua Fu Chan Ke Za Zhi 1998; 33: 17-19

[38] Keenan JA, Chen TT, Chadwell NL et al. IL-1 beta, TNF-alpha, and IL-2 in peritoneal fluid and macrophage-conditioned media of women with endometriosis. Am J Reprod Immunol 1995; 34: 381-385

[39] Benson S, Janssen OE, Hahn S et al. Obesity, depression, and chronic lowgrade inflammation in women with polycystic ovary syndrome. Brain Behav Immun 2008; 22: 177-184

[40] Krishna MB, Joseph A, Subramaniam AG et al. Reduced Tregs in peripheral blood of PCOS patients - a consequence of aberrant II2 signaling. J Clin Endocrinol Metab 2015; 100: 282-292

[41] Garzia E, Clauser R, Persani L et al. Prolactin and proinflammatory cytokine expression at the fetomaternal interface in first trimester miscarriage. Fertil Steril 2013; 100: 108-115.e2

[42] Alfer ], Happel L, Dittrich R et al. Insufficient Angiogenesis: Cause of Abnormally Thin Endometrium in Subfertile Patients? Geburtsh Frauenheilk 2017; 77: 756-764

[43] Sherwin JR, Smith SK, Wilson A et al. Soluble gp130 is up-regulated in the implantation window and shows altered secretion in patients with primary unexplained infertility. I Clin Endocrinol Metab 2002; 87: 3953-3960 